\title{
Methods of Transvaginal Ultrasound Examination in Endometriosis
}

\author{
Alexandra Bruja ${ }^{1,2}$, Lacramioara Brinduse ${ }^{2,3}$, Ovidiu Bratu $^{2,4,5}$, Camelia Diaconu², Elvira Bratila ${ }^{1,2}$
}

\begin{abstract}
Endometriosis is a condition associated with pain and infertility. The gold standard for the diagnosis of endometriosis is visual examination by laparoscopy, preferably with histological confirmation. There is often a significant delay in the diagnosis of this disease. The imaging care assay which confirms the presence of an ovarian endometriosis cyst or profoundly infiltrative endometriosis can help guide surgical treatment approaches. There are studies that support that expert-guided transvaginal ultrasound (ETVU) is more sensitive than routine pelvic ultrasound in the diagnosis of endometriosis, especially in the non-ovarian form.
\end{abstract}

Keywords: endometriosis, transvaginal ultrasound, diagnosis

\section{Rezumat}

Endometrioza este o patologie asociată cu durere și infertilitate. Standardul de aur pentru diagnosticul de endometrioză este examinarea vizuală prin laparoscopie, de preferință cu biopsie și confirmare histologică. Există adesea o întârziere semnificativă în diagnosticarea acestei boli. Examenul imagistic care confirmă prezența unui chist ovarian endometriozic sau o endometrioză profund infiltrativă poate ajuta la ghidarea abordărilor terapeutice chirurgicale. Există studii care susțin că ecografia transvaginală (ETV) ghidată de experți este mai sensibilă decât ultrasonografia pelvină efectuată de rutină în diagnosticul de endometrioză, în special în forma non-ovariană.

Cuvinte cheie: endometrioza, ecografie transvaginală, diagnostic

\section{INTRODUCTION}

„Endometriosis is a chronic, hormone-dependent condition with a nonspecific clinical picture, including chronic pelvic pain, a disturbing symptom that causes the patient to seek specialist medical advice" ${ }^{1}$. It is a chronic, often progressive, condition that affects women of reproductive age in a proportion of $5-10 \%$. Despite such high prevalence, endometriosis remains an enigmatic disease with a poorly understood pathophysiology. Symptoms such as dysmenorrhea, dyspa- reunia, dysuria, chronic pelvic pain and infertility associated with endometriosis are often debilitating and have a major negative impact on women's sex life, self-esteem and quality of life ${ }^{1-3}$. ,Endometriosis can be considered a pathology characterized by the presence outside the uterine cavity of parasite-like endometrial tissue fragments, for its ability to implant and maintain its functionality in almost all parts of the human body. Extrapelvic involvement is rare without previous pelvic surgery with a wide range of clinical symptoms"

\footnotetext{
${ }^{1}$ „Prof. Dr. Panait Sarbu" Clinical Hospital Obstetrics and Gynecology, Bucharest, Romania

2 "Carol Davila" University of Medicine and Pharmacy, Bucharest, Romania

${ }^{3}$ Department of Public Health and Management, Bucharest,

Romania

${ }^{4}$ Clinic of Urology, Emergency University Central Military Hospital,

Bucharest, Romania

${ }^{5}$ Academy of Romanian Scientists, Bucharest, Romania
}

\section{Corresponding author.}

Elvira Bratila, „Prof. Dr. Panait Sarbu” Clinical Hospital Obstetrics and Gynecology, Bucharest, Romania.

E-mail: elvira.bratila@umfcd.ro 
The revised classification by the American Society for Reproductive Medicine (ASRM) is the most accepted staging system for endometriosis, although there is no consensus on defining the degree of severity in endometriosis ${ }^{5-7}$.

The organs most commonly affected by endometriosis are ovaries and pelvic peritoneum, followed by profound infiltration sites. Deep infiltrated endometriosis (DIE) is defined by the presence of endometrial implants, fibrosis and muscle hyperplasia under the peritoneum $(>5 \mathrm{~mm})$ and involves, in decreasing order of frequency, uterusacral ligaments, rectosigmoid colon, vagina and bladder ${ }^{8,9}$.

\section{DIAGNOSIS}

Diagnosis of endometriosis remains a dilemma due to the nonspecific nature of the symptoms and the difficulty in distinguishing pelvic pain due to endometriosis to that caused by pelvic infection or non-gynecological diseases such as urological, gastrointestinal or musculoskeletal diseases. This results in a considerable diagnostic delay, with a considerable deterioration in quality of life and high psychological morbidity,8,10.

Causes of dyspareunia, dyskinesia and infertility among women with endometriosis could be attributed to adhesions between the posterior wall of the uterus, cervix or vagina and the anterior wall of the rectosigmoid. It was found that, although there is an association between endometriosis and infertility (prevalence of about 30\%), a causal relationship between them remains controversial, especially in the case of minimal or mild endometriosis. „Umbilical endometriosis rarely occurs and can be misdiagnosed as umbilical hernia. The standard treatment in this situation is omphalectomy and the reconstruction of the abdominal walls with prosthetic materials preventing both umbilical hernia and the relapse of endometriosis”11. „Bladder endometriosis is the most common form of urinary tract endometriosis. Diagnosis is delayed due to nonspecific symptoms”12. „Ureteral involvement in pelvic organs endometriosis can be an unfortunate, but rare and ignored pathology. Preoperative assessment of urinary tract damage in patients with endometriosis is important. The surgical laparoscopic approach is based on the extent of the disease and can be performed successfully by a highly experienced surgeon"13-21. Therefore, early detection of endometriosis in infertile patients is important for treatment modalities. Because adequate assessment of patients with symptoms suggestive of endometriosis is of particular importance and physical examination has a reduced capacity to diagnose endometriosis due to pain, obesity and patient injuries that are inaccessible to touch, imaging techniques are mandatory for diagnosis ${ }^{8,22}$.

In the past decades, a non-invasive pre-operative diagnosis for endometriosis is possible, following advances in imaging methods such as ultrasound and magnetic resonance imaging (MRI). The value of ultrasound was determined in the diagnosis of ovarian endometriosis. Endoscopic rectal sonography (ERS), transrectal ultrasound (TRU), and transvaginal sonography (TVS) have been shown to be useful in diagnosing non-ovarian endometriosis such as intestinal, bladder and uterus-like ligaments. A recent study has demonstrated the high degree of precision for TVS when combined with bimanual assessment for the diagnosis of deep pelvic endometriosis. In addition, three other studies have shown that TVS is comparable, or even superior to, MRI in the diagnosis of endometriosis ${ }^{5,6,22}$.

Although endometriosis is a common pathology, therefore a significant burden on society, the average diagnosis delay from the onset of symptoms is often 6 to 10 years. Therefore, it is essential to consider efforts that can reduce the delay of diagnosis and can help patients address specialists in the field. Early diagnosis of endometriosis should be combined with an accurate assessment of the extent of the disease, which in turn can help prepare for surgery when necessary. Exact preoperative evaluation can help reduce the number of incomplete or failed surgeries due to inadequate knowledge of the magnitude and severity of the disease and also direct referrals to centers or specialists if necessary ${ }^{2,15,24}$.

Laparoscopy is the gold standard for the diagnosis of endometriosis. Also, histological confirmation is not always obtained. However, diagnostic laparoscopy requires general anesthesia and is associated with a risk of minor complications of approximately 3\% (nausea, vomiting or shoulder pain) and a major complication risk (eg gut perforation) of $0.5 \%$. Also, the extent of endometriosis may be overestimated or underestimated due to varying the size, depth and localization of the lesion ${ }^{8}$.

"The combination of MRI with computerized tomography-virtual colonoscopy leads to improved accuracy in the preoperative evaluation of colorectal endometriosis and in the subsequent preoperative choice of surgical procedures for the digestive tract" 25 . 


\section{TRANSVAGINAL ULTRASOUND- EXAMINATION TYPES}

Transvaginal ultrasound (TVU) is the first-line imaging method recommended for the evaluation of endometriosis; however, the limitations of this approach have been well documented in the literature. It has been demonstrated that conducting an expert guided transvaginal ultrasound (EGTVU) has improved the rate of endometriosis detection and can provide a preoperative assessment of the extent of the disease, especially in cases of deep disease. Recently, ESHRE guidelines support the role of TVS performed by clinicians with experience in the diagnosis of endometriosis, other forms of endometriosis than ovarian ${ }^{23,24,26}$.

Routine TVS was defined as a pelvic scan carried out by a sonographer recording still images and videos, which are read later by a radiologist or a gynecologist. All reports must have a "satisfactory" image quality to allow proper reporting ${ }^{23,27}$.

Expert-guided TVS has been defined as a dynamic real-time scan by an expert clinician in endometriotic lesion ultrasonography. Before performing ultrasound, the sonographer knows the clinically relevant history of endometriosis-related symptoms. Each patient is subjected to a methodical ultrasound examination in the following order: a) Complete suprapubic pelvic ultrasound for the assessment of uterine position, size and morphology, as well as the position of the ovaries; posterior sac bottom; the presence of the pelvic mass. b) Limited kidney abdominal ultrasound to document kidney size and morphology (ie assessment for hydroureteronephrosis) c) Subdivision reporting of endometriotic lesions including anterior, middle and posterior positions $^{23,26}$.

„TVS with saline solution is a combination of TVS and the introduction into the vagina of a saline solution that creates an acoustic window between the transvaginal probe and the surrounding vaginal structures. Thus, a better visualization of the pelvic posterior compartment is obtained ${ }^{28}$. When replacing the ultrasound gel with saline solution, it has the advantage of lessening the discomfort of the patient and no need for a second examiner to help. Ultrasound gel TVS is an investigation successfully used in the diagnosis of endometrioticlesions of the posterior pelvis" 28 .

Conventionally, an ultrasound scan will report the presence or absence of structural anomalies such as ovarian cysts or hydrosalpinx (considered major markers). Other information is available for the presence or absence of pelvic pathology based on minor markers (eg, degree of ovarian motility, sensitivity or Douglas bag). These results are usually not reported during routine scanning. However, they have the potential to improve the efficacy of the TVS diagnosis ${ }^{8,29}$.

The standard and systematic way of evaluating through transvaginal ultrasound the patients who associate symptoms that suggest a possible diagnosis of endometriosis is the following. First, the uterus is assessed in transversal and sagittal plans and the ability to rectify the uterine position is observed. Second: the ovaries are examined and evaluated: (a) the dimension is measured in 3 orthogonal planes (b) mobility: through a combination of light pressure with the vaginal probe and the exerted pressure exerted by the examiner's hand. The ovaries may be either mobile (the ovaries may be seen sliding over the surrounding structures without resistance) or fixed and fixed either on the uterus or on the iliac vessels. (c) examine the level of ovaries: at the same level and, if not, which is the upper (left or right). In case of non-visualization of the ovary due to its high level, abdominal ultrasound can be used to exclude congenital absence. The peritoneum covering the vesicle sac, the Douglas $\mathrm{sac}$, the intestine, the rectocervical and the rectovaginal sac are examined for the presence of the peritoneal cyst. The Douglas bag is evaluated for the presence of free fluid and for complete obliteration, which has been defined as the absence of any glide between seros on the posterior cervix or uterus and bowel when the uterus is easily mobilized by a combination of pressure on the cervix with the transvaginal probe alternating with the pressure exerted on the uterus by the free hand of the examiner through the abdominal wall. Finally, the vaginal probe is inserted into the posterior fornix and the patient is asked to report on the onset of any sensitivity experienced during the pressure exerted by the probe in the posterior fornix for the detection of endometriosis lesions, the so-called transvaginal guided sensitivity sonography $y^{8,22}$.

„The Doppler ultrasound examination is used to target tumor circulation. Doppler ultrasound in pulsatile mode must highlight the resistance and pulsatility index in peritumoral circulation and intrachistic formations" 30 .

There is a significant association between the diagnosis of endometriosis and the following ultrasound findings: Ovarian fixation to the uterus, the ovaries are not located at the same level, and the left ovary is located above, the ovarian fixation to the iliac vessels, 
the left ovary unseen, and the sensitivity to the transvaginal examination. These markers have been shown to have the highest degree of precision in diagnosing endometriosis and could be considered positive diagnostic markers ${ }^{7,8}$. Ovarian fixation can be attributed to adhesions of either uterus or iliac vessels. Guerriero et al. found that ovarian motility was the most accurate marker for pelvic adhesions. Probe pressure is the most accurate method for measuring ovarian motility that is not affected by patient habitus. Regarding the sensitivity (pain) associated during ultrasound examination, Okara et al. assessed the accuracy of TVS in the detection of common pelvic pathologies in women with chronic pelvic pain using two ultrasound markers (ovarian mobility and ovarian sensitivity) after exclusion of the patients with major positive ultrasound markers (endometrioma or hydrosalpinx). They found that the use of minor ultrasound markers can improve TVS sensitivity in endometriosis diagnosis from 34\% to $87 \%$ with a $84 \%$ negative predictive value (NPV), and reported that patients with abnormal ultrasound had ovaries fixed and more sensitive than those with normal scanning. Also, many studies have used painguided TVS to detect deep implants of endometriosis. The fact that the left ovaryis located upper can be attributed to the presence of the sigmoid colon on the left side, which leads to a decrease in the movement of the peritoneal fluid but also to the anatomical difference between left and right hemipelvis. Moreover, th left ovary located upper can be explained by repeated inflammation in the peritoneal surface, which is maximized on the left side due to the presence of the sigmoid colon. These results in shorter peritoneal lining of the left infundibulopelvic ligament and lengthening of the left ovary, in addition to the perisigmoid adhesions observed in endometriosis cases 8,29 .

The presence of ultrasound minor markers (incapacity to rectify the uterine position, free Douglas bag fluid, peritoneal cyst and Douglas sac assembled) associate low sensitivity although they have a high specificity. Therefore, they may be considered negative markers of endometriosis (negative minor markers). However, their absence cannot rule out endometriosis as their frequency is low $^{8}$.

Endometrial nodules (or DIE) are usually visualized as a solid, hypoechoic or isoechogenic sterile mass with irregular, painful palpable outer edges and fixed to surrounding pelvic structures. They are usually located in the uterus, ligaments, the rectovaginal septum and the bladder. Endometrial nodules located in the wall of the rectosigmoid colon tend to appear as hypoechoic thickening of their own intestinal muscles, which sometimes go out into the intestinal lumen ${ }^{5,6}$.

The treatment options in this pathology, although there are multiple, the rate of relapse is high. „Oral drug therapy with desogestrel $0.075 \mathrm{mg}$ has been shown to be effective in endometriosis acting at the molecular level by decreasing $\mathrm{Ki}-67$ expression, which translates clinically by alleviating symptoms, decreasing the size of the endometrium and improving operator conditions” ${ }^{31}$. „The use of long-term dienogest has led to a progressive decline in pelvic pain and vaginal bleeding associated with endometriosis during treatment, with maintenance of this aspect after discontinuation of treatment, in premenopausal patients with recurrent peritoneal and rectosigmoidendometrial lesions" $32-39$.

\section{CONCLUSIONS}

TVS appears to be a useful imaging method for predicting endometriosis. However, training, skills and passion are prerequisites for the examining sonographer. The use of ultrasonographic minor markers in women with symptoms suggestive of endometriosis improves our ability to predict or rule out the presence of endometriosis. This helps reduce the vigilant waiting period before active management, as well as counseling patients about fertility decisions ${ }^{8,9}$.

„Malignancy of endometrial lesions, rarely present, leads to management problems when dysplasia is highlighted in the histopathological examination. Immunohistochemistry and electron microscopy are essential in achieving these therapeutic decisions, ${ }^{40}$.

It is recommended to use minor ultrasound markers, either alone or in combination, for the appropriate selection of patients for subsequent investigations. This would reduce the number of laparoscopies performed in these patients, which would lead to a shorter, safer, and more cost-effective hospitalization ${ }^{8,29}$.

TVS is a useful diagnostic imaging method for assessing the severity of pelvic endometriosis, is accurate in the detection of severe disease. This could make it easier for women to benefit of proper surgical care ${ }^{24,27}$.

Expert guided TSV is more sensitive than routine pelvic ultrasound performed in the diagnosis of endometriosis, especially in the non-ovarian form. It also provides a detailed description of the extent and severity of the disease, which can help with surgical planning and patient counseling ${ }^{23,27}$. 
„Although there are many available therapeutic and surgical methods of treatment, endometriosis treatment needs to be individualized according to each case, including the immunohistochemical analysis of endometriosis' implants" ${ }^{41}$.

\section{References}

1. O. M. Bodean, D. Voicu, O. Munteanu, E. Bratila, R. Bohaltea, D. V. Davitoiu, M. Cirstoiu. Chronic Pelvic Pain and Endometriosis. Research and Science Today. 2015; 10(2): 206-214

2. Nnoaham KE, Hummelshoj L, Webster P, D'Hooghe T, De CiccoNardone F, De CiccoNardone C, Jenkinson C, Keneddy SH, Zondervan KT. Impact of endometriosis on quality of life and work productivity: A multicenter study across ten countries. FertilSteril. 2011;96: 366-373).

3. Walsh JW, Taylor KJW, Rosenfield AT. Gray scale ultrasonography in the diagnosis of endometriosis and adenomyosis. Am J Roentgenol.1979; 132:87-90.

4. M. Antonovici, S. Ionescu, O. Ionescu, E. Brătilă, C. Mehedințu, M. Plotogea. Extrapelvic endometriosis - our experience. Revista Ginecologia.ro Anul III, Nr. 10, Decembrie 2015 (4/2015), pg. 34-36

5. T.K. Holland, J. Yazbek, A. Cutner, E. Saridogan, W. L. Hoo, D. Jurkovic. Value of transvaginal ultrasound in assessing severity of pelvic endometriosis.Ultrasound Obstet Ginecol. 2010; 36: 241-248.

6. Moore J, Copley S, Morris J, Lindsell D, Golding S, Kennedy S. A systematic review of the accuracy of ultrasound in the diagnosis of endometriosis. Ultrasound ObstetGynecol 2002; 20: 630-634

7. Hudelist G, Oberwinkler KH, Singer CF, Tuttlies F, Rauter G, Ritter $\mathrm{O}$, Keckstein $\mathrm{J}$. Combination of transvaginal sonography and clinical examination for preoperative diagnosis of pelvic endometriosis. Hum Reprod 2009; 24: 1018-1024.

8. Tamer H. Said, Amal Z. Azzam. Prediction of endometriosis by transvaginal ultrasound in reproductive-age women with normal ovarian size.Middle East Fertility Society Journal. 2014; 19(3): 197-207.

9. S. Cheewadhanaraks, K. Peeyananjarassri, K. Dhanaworavibul, T. Liabsuetrakul Positive predictive value of clinical diagnosis of endometriosis. J Med Assoc Thai, 87 (2004), pp. 740-744

10. C. Chapron, J.B. Dubuisson, V. Pansini, M. Vieira, A. Fauconnier, $H$. Barakat, et al. Routine clinical examination is not sufficient for diagnosing and locating deeply infiltrating endometriosis. J Am AssocGynecolLaparosc, 9 (2002), pp. 115-119

11. Elvira Bratila, Oana-Maria Ionescu, Dumitru-Cristinel Badiu, Costin Berceanu, Simona Vladareanu, Doina Mihaela Pop, Claudia Mehedintu. Umbilcal hernia masking primary umbilical endometriosis - a case report. Rom J Morphol Embryol 2016. 57(2):825-829

12. Coroleucă Ciprian-Andrei, Brătilă Elvira, Brătilă Petre, Hudiță Decebal, Stănculescu Ruxandra, Comandașu Diana, Coroleucă Cătălin-Bogdan. Lower urinary tract symptomatology in deep infiltrating and bladder endometriosis. The 13th National Congress of Urogynecology, Proceedings of UROGYN, 2016 Filodiritto Publisher, ISBN 978-88-95922-78-2 pag 83-86

13. Laparoscopic Ureterolysis in the Management of Deep and Infiltrative Pelvic Endometriosis - Case report. Mehedintu Claudia,

\section{Compliance with ethics requirements:}

The authors declare no conflict of interest regarding this article.

The authors declare that all the procedures and experiments of this study respect the ethical standards in the Helsinki Declaration of 1975, as revised in 2008(5), as well as the national law. Informed consent was obtained from all the patients included in the study.

Diaconu Victor, Secureanu Adrian Florin, Ionescu Sorin, Bratila Elvira, Berceanu Costin, Cirstoiu Monica Mihaela, Antonovici Marina Rodica, Plotogea Mihaela Nicoleta, Ionescu Oana Maria. The 13th National Congress of Urogynecology, Proceedings of UROGYN, 2016 Filodiritto Publisher, ISBN 978-88-95922-78-2 pag 164-169

14. Value of ultrasound elastography in the diagnosis of native kidney fibrosis - Peride I, Rădulescu D, Niculae A, Ene V, Bratu OG, Checherită IA. - Med Ultrason. 2016 Sep;18(3):362-9

15. Calcific uremic arteriolopathy in hemodialyzed patients. - Checherită IA, Smarandache D, Rădulescu D, Peride I, Bratu O, Ciocâlteu A, Sebe I, Lascăr I. - Chirurgia (Bucur). 2013 Sep-Oct 108(5):736-40

16. Difficulties in diagnosis and surgical treatment of a giant retroperitoneal lipoma. - Constantinoiu S, Bârlă R, losif C, Cociu L, Gîndea C, Hoară P, Bratu O, Rușitoru L. - Chirurgia (Bucur). 2009 May-Jun;104(3):363-7

17. Renal artery bilateral arteriosclerosis cause of resistant hypertension in hemodialysed patients. - Niculae A, Peride I, Marinescu-Paninopol A, Vrabie CD, Ginghină O, Jecan CR, Bratu OG

18. Vitamin $\mathrm{K}$ influence on cardiovascular mortality in chronic hemodialysed patients - Rădulescu D, Balcangiu Stroescu A Pricop C, Geavlete B, Negrei C, Bratu O, Ginghină O, Văcăroiu I-Revista de Chimie, vol. 68, nr. 1, 2017

19. Mullerianosis of the urinary bladder: a rare case report and review of the literature - Stanimir M, Chiutu LC, Wese S, Milulescu A, Nemes RN, Bratu O - Rom J Morphol Embryol. 2016;57(2 Suppl):849-852.

20. Nephrotic syndrome secondary to amyloidosis in a patient with monoclonal gammopathy with renal significance (MGRS) - Andrei Niculae, Ileana Peride, Vlad Vinereanu, Daniela Rădulescu, Ovidiu Gabriel Bratu, Bogdan Florin Geavlete, Ionel Alexandru Checheriță - Rom J Morphol Embryol. 2017;58(3).

21. Synthesis and Characterization of Novel $\mathrm{Cu}(\mathrm{II}), \mathrm{Pd}(\mathrm{II})$ and $\mathrm{Pt}(\mathrm{II})$ Complexes with 8-Ethyl-2-hydroxytricyclo(7.3.1.0(2,7))tridecan-13-one-thiosemicarbazone: Antimicrobial and in Vitro Antiproliferative Activity. - Pahonțu E, Paraschivescu C, Ilieș DC, Poirier D, Oprean C, Păunescu V, Gulea A, Rosu T, Bratu O. - Molecules. 2016 May 21;21(5). pii: E674. doi: 10.3390/molecules21050674.

22. Ohba T, Mizutani H, Maeda T, Matsuura K, Okamura H. Evaluation of endometriosis in uterosacral ligaments by transrectal ultrasonography. Hum Reprod 1996; 11: 2014-2017.

23. Margaret Ann Fraser, SugandhaAgaerwal, Innie Chen, Sukhbir Sony Singh. Routine vs. expert-guided transvaginal ultrasound in the diagnosis of endometriosis. A retrospective review. Abdom Imaging. 2015; 40(3): 587-594.

24. Sandler MA, Karo JJ. The spectrum of ultrasonic findings in endometriosis.Radiology.1978; 127:229-231.

25. C. Mehedintu, L.A. Branduse, E. Bratila, M. Monroc, E. Lemercier E. Suaud, C. Collet-Savoye, H. Roman. Does Computed Tomo- 
graphy-Based Virtual Colonoscopy Improve the Accuracy of Preoperative Assessment Based on Magnetic Resonance Imaging in Women Managed for Colorectal Endometriosis. Journal of Minimally Invasive Gynecology, 2018

26. Bazot M, Lafont C, Rouzier R, Roseau G, Thomassin-Naggara I, Daraï E. Diagnostic accuracy of physical examination, transvaginal sonography, rectal endoscopic sonography, and magnetic resonance imaging to diagnose deep infiltrating endometriosis. FertilSteril. 2009; 92:1825-1833.

27. Denny E, Mann CH. Endometriosis-associated dyspareunia: the impact on women's lives. J Fam Plan Reprod Heal Care. 2007; 33:189-193.

28. Elvira Brătilă, Diana-Elena Comandașu, Ciprian Coroleucă, Monica Mihaela Cîrstoiu, Costin Berceanu, Claudia Mehedintu, PetreBratila, Simona Vladareanu. Diagnosis of endometriotic lesions by sonovaginography with ultrasound gel. Med Ultrason 2016, 18 (4), 469-474.

29. Guerriero S, Ajossa S, Gerada M, D'Aquila M, Piras B, Melis GB "Tenderness-guided" transvaginal ultrasonography: a new method for the detection of deep endometriosis in patients with chronic pelvic pain. FertilSteril 2007; 88: 1293-1297.

30. Elvira Bratila. Catalin Bogdan Coroleuca, Ciprian Andrei Coroleuca, Diana-Elena Comandasu, Claudia mehedintu, Mihai Mitran, CostinBerceanu. Rolul Examinarii Doppler in evaluareapatologieiovariene.UltrasonografiaGinecologica, 2016

31. C. Mehedintu, M, Antonovici, L. Brinduse, E. Bratila, R. Stanculescu, C. Berceanu, O. Bratu, S. Pituru, M. Onofriescu, D. Roxana Matasaru. The influence of Progesterone on Immunohystochemical Markers in Endometriosis. Revista de chimie, 2018

32. E. Bratila, R. Stanculescu, V. Bausic, D-E.Comandasu.Efficacy of long-term dienogest treatment for endometriosis recurrency in premenopausal women. The European Menopausal Journal, 2015, 81(1):172

33. Solitary cecum diverticulitis - A surprising diagnosis - Bogdan Socea, Anca A. Nica, Cristian A. Smaranda, Alexandru C. Carâp, Laura I. Socea, Mihai Dimitriu, Ovidiu G. Bratu, Cezar E. Moculescu, Serban V.G. Berteșteanu, Vlad D. Constantin - Archives of the Balkan Medical Union, Vol. 52, Iss. 4, 2017
34. Incidental finding of a sigmoid intussusception associated with rectal prolapse-a case report - Bogdan Socea, Anca Nica, Ovidiu Bratu, Camelia Diaconu, Alexandru Smaranda, Laura Socea, Serban Bertesteanu, Mihai Dimitriu, Alexandru Carap, Vlad Constantin - Archives of the Balkan Medical Union, Vol. 53, Iss. 1 , 2018

35. Superior vena cava syndrome - Paraschiv B, Dediu G, lancu A Bratu O, Diaconu C - Archives of the Balkan Medical Union, vol. 52, No. 1, 2017

36. Radionuclide Imaging. An Update on the Use of Dynamic Renal Scintigraphy - Raluca Mititelu, Ovidiu Bratu - Modern Medicine, vol. 24, No. 4, 2017

37. Spiegel hernia - Case presentation - Bogdan Socea, Alexandru Smaranda, Anca Nica, Ovidiu Bratu, Camelia Diaconu, Laura Socea, Dan Dumitrescu, Mihai Dimitriu, Alexandru Carap, Vlad Constantin - Archives of the Balkan Medical Union, Vol. 53, Iss. 1,2018

38. Liver abnormalities in patients with heart failure - Teodora Draghici, Lucian Negreanu, Ovidiu Bratu, Radu Tincu, Bogdan Socea, Mihaela Iancu, Ana Maria Stanescu, Camelia Diaconu Archives of the Balkan Medical Union, Vol. 53, Iss. 1, 2018

39. Castleman's Disease-Clinical, Histological and Therapeutic Features - Radu Dragos Marcu, Arsenie Dan Spinu, Bogdan Socea, Maria Oana Bodean, Camelia Cristina Diaconu, Florina Vasilescu, Tiberiu Paul Neagu, Ovidiu Gabriel Bratu - Revista de Chimie, vol. 2018, nr. 4, 2018

40. V. Constantin, A. Carap, S. Bobic, I. Paun, E. Bratila, B. Socea A-M Morosanu, N. Mirancea. Accurate Diagnosis of Sigmoid Colon Endometriosis by Immunohistochemistry and Transmission Electron Microscopy- A Case Report. Chirurgia, 2015; 110:482-485

41. Laparoscopic Ureterolysis in the Management of Deep and Infiltrative Pelvic Endometriosis - Case report. Mehedintu Claudia Diaconu Victor, Secureanu Adrian Florin, IonescuSorin, Bratila Elvira, BerceanuCostin, Cirstoiu Monica Mihaela, Antonovici Marina Rodica, PlotogeaMihaelaNicoleta, IonescuOana Maria. The 13th National Congress of Urogynecology, Proceedings of UROGYN, 2016 Filodiritto Publisher, ISBN 978-88-95922-78-2 pag 164-169 